\title{
Measurement of PM and its chemical composition in real-world emissions from non-road and on-road diesel vehicles
}

\author{
Min Cui ${ }^{1}$, Yingjun Chen ${ }^{1}$, Yanli Feng ${ }^{2}$, Cheng $\mathrm{Li}^{3}$, Junyu Zheng ${ }^{4}$, Chongguo Tian ${ }^{5}$, Caiqing Yan $^{6}$, and Mei Zheng \\ ${ }^{1}$ Key Laboratory of Cities' Mitigation and Adaptation to Climate Change in Shanghai (China Meteorological \\ Administration), College of Environmental Science and Engineering, Tongji University, Shanghai, China \\ ${ }^{2}$ Institute of Environmental Pollution and Health, School of Environmental and Chemical Engineering, Shanghai University, \\ Shanghai, China \\ ${ }^{3}$ Laboratory for Atmospheric Research and Environmental Simulation School of Environment and Energy, South China \\ University of Technology, Guangzhou, China \\ ${ }^{4}$ School of Environment and Climate, Jinan University, Guangzhou, China \\ ${ }^{5}$ Key Laboratory of Coastal Zone Environmental Processes and Ecological Remediation, Yantai Institute of Coastal Zone \\ Research, Chinese Academy of Sciences, Yantai, China \\ ${ }^{6}$ SKL-ESPC and BIC-EAST, College of Environmental Sciences and Engineering, Peking University, Beijing 100871, China
}

Correspondence to: Yingjun Chen (yjchentj@tongji.edu.cn), Yanli Feng (fengyanli@shu.edu.cn), and Junyu Zheng (zhengjunyu_work@ hotmail.com)

Received: 22 November 2016 - Discussion started: 6 December 2016

Revised: 27 April 2017 - Accepted: 28 April 2017 - Published: 9 June 2017

\begin{abstract}
With the rapid growth in the number of both non-road and on-road diesel vehicles, the adverse effects of particulate matter (PM) and its constituents on air quality and human health have attracted increasing attentions. However, studies on the characteristics of PM and its composition emitted from diesel vehicles are still scarce, especially under real-world driving conditions. In this study, six excavators and five trucks that provided a wide range of emission standards and operation modes were tested, and PM emissions and their constituents - including organic carbon (OC), elemental carbon (EC), water-soluble ions (WSIs), elements, and organic species like polycyclic aromatic hydrocarbons (PAHs), n-alkanes, and hopanes - as well as steranes were analyzed and characterized. The average emission factors for PM (EFPM) from excavator and truck emissions were $829 \pm 806$ and $498 \pm 234 \mathrm{mg} \mathrm{kg}^{-1}$ fuel, respectively. $\mathrm{EF}_{\mathrm{PM}}$ and $\mathrm{PM}$ constituents were significantly affected by fuel quality, operational mode, and emission standards. A significant correlation $\left(R^{2}=0.79, p<0.01\right)$ was found between $\mathrm{EF}_{\mathrm{PM}}$ for excavators and the sulfur contents in fuel. The highest average $\mathrm{EF}_{\mathrm{PM}}$ for working excavators was $904 \pm 979 \mathrm{mg} \mathrm{kg}^{-1}$ fuel as a higher engine load required in this mode. From pre-stage 1 to stage 2, the average EFPM for
\end{abstract}

excavators decreased by $58 \%$. For trucks, the average nonhighway $\mathrm{EF}_{\mathrm{PM}}$ at $548 \pm 311 \mathrm{mg} \mathrm{kg}^{-1}$ fuel was higher than the highway $\mathrm{EF}_{\mathrm{PM}}$ at $497 \pm 231 \mathrm{mg} \mathrm{kg}^{-1}$ fuel. Moreover, the reduction rates were 63.5 and $65.6 \%$ when switched from China II and III to China IV standards, respectively. Generally, the PM composition emitted from excavators was dominated by OC (39.2 $\pm 21.0 \%)$ and EC $(33.3 \pm 25.9 \%)$; PM from trucks was dominated by EC $(26.9 \pm 20.8 \%)$, OC $(9.89 \pm 12 \%)$, and WSIs $(4.67 \pm 5.74 \%)$. The average $\mathrm{OC} / \mathrm{EC}$ ratios for idling and working excavators were 3 to 4 times higher than those for moving excavators. Although the EFPM for excavators and trucks was reduced with the constraint of regulations, the element fractions for excavators increased from $0.49 \%$ in pre-stage 1 to $3.03 \%$ in stage 2, and the fraction of WSIs for the China IV truck was 5 times higher than the average value of all other-level trucks. Furthermore, as compared with other diesel vehicles, wide ranges were found for excavators of the ratios of benzo[a]anthracene / (benzo[a]anthracene + chrysene) (0.26-0.86), indeno[1,2,3-cd]pyrene / (indeno[1,2,3cd]pyrene + benzo[ghi]perylene) (0.20-1.0), and fluoranthene / (fluoranthene + pyrene) (0.24-0.87), which might be a result of the complex characteristics of the excavator 
operation modes. A comparison of our results with those in the literature revealed that on-board measurement data more accurately reflect actual conditions. Although the fractions of the 16 priority PAHs in PM from the excavator and truck emissions were similar, the equivalent concentrations of total benzo[a]pyrene of excavators were 31 times than that for trucks, implying that more attention should be paid to non-road vehicle emissions.

\section{Introduction}

Particulate matter (PM) emitted from diesel vehicles has significant adverse effects on air quality, human health, and global climate change and therefore merits close examination (Aggarwal and Jain, 2015; Longhin et al., 2016). Previous studies have found that diesel vehicle exhaust is a major source of ambient fine PM emissions $\left(D_{\mathrm{p}} \leq 2.5 \mu \mathrm{m}\right)$ (Oanh et al., 2010; Zhang et al., 2015). For example, vehicle exhaust was reported to contribute almost $30 \%$ of ambient $\mathrm{PM}_{2.5}$ in nine Chinese cities in 2015 (MEP, 2016). The International Agency for Research on Cancer (IARC) reported that exposure to diesel exhaust can cause lung cancer (IARC, 2012). Adar et al. (2015) surveyed more than 25 million children and concluded that a disproportionate number of cases of respiratory disease were caused by breathing polluted air from diesel school buses. Moreover, nearly $34 \%$ of element carbon (EC) emissions, a major contributor to current global warming and poor human health, originates from off-road diesel vehicle emissions in the United States (USEPA, 2015).

The numbers of on-road and non-road diesel vehicles have increased considerably in China and have caused severe environmental problems. On-road diesel vehicles can be classified into light-duty, medium-duty, and heavy-duty trucks. Non-road diesel vehicles mainly include construction machinery and agricultural equipment (MEP, 2014). Airplanes, trains, and vessels are not included as non-road diesel vehicles in this study because diesel is not the primary fuels used for these vehicles. The number of on-road diesel vehicles increased from 11.0 million in 2009 to 32.8 million in 2015, while the number of non-road diesel vehicles increased from 20.6 million in 2006 to 33.6 million in 2012 (CCCMIY and CCMA, 2013; MEP, 2016). According to China's vehicle environmental management annual report for 2015 (MEP, 2016), 0.56 million $t$ of $\mathrm{PM}_{2.5}$ was emitted from on-road mobile sources, $90 \%$ of which originated from on-road diesel vehicle emissions (Fig. S1 in Supplement). However, pollutants emitted from non-road diesel vehicles should not be neglected. In 1991, the US Environmental Protection Agency (USEPA) published a report indicating that PM emitted from non-road diesel vehicles was significantly higher than that emitted from on-road diesel vehicles (USEPA, 1991). Wang et al. (2016) compiled an emission inventory for non-road equipment, including agricultural equipment, river/ocean- going vessels, locomotives, and commercial airplanes, and they found that $349 \mathrm{Gg}$ of PM was emitted from non-road vehicles in China during 2012. Construction equipment was the largest non-road diesel vehicles emission source. Zhang et al. (2010) reported that $\mathrm{PM}_{10}$ emitted from construction equipment in the Pearl River Delta region accounted for $26.5 \%$ of the total emissions from non-road vehicles in 2006. The construction equipment in use increased from 1.97 to 5.85 million between 2006 and 2012 (CCCMIY and CCMA, 2013). Furthermore, excavators, one of the most abundant types of construction equipment (Fig. S1), contributed almost $65 \%$ of the PM emissions from construction equipment (Li et al., 2012).

In order to control PM emission pollution from diesel vehicles, China began to implement emission standards in early 2001 for light- and heavy-duty diesel vehicles (SEPA and SAQSIQ, 2001). These standards were tightened in the subsequent 12 years, from the China I to China V standards. Although the China V emission standard for on-road diesel vehicles has been formulated, insufficient diesel fuel quality has slowed their implementation (Yue et al., 2015). In addition, the China IV emission standards for on-road diesel vehicles have not been fully implemented. Moreover, the implementation timeline of emission standards for non-road diesel vehicles has lagged behind that for on-road diesel vehicles. China implemented two emission standards for new non-road diesel engines, stages 1 and 2 in 2007 and 2009, respectively. However, the first implementation in China was 7 years later than that in the United States (USEPA, 2003; SEPA and SAQSIQ, 2007). The pollution emission limits for on-road and non-road diesel vehicles are given in Tables S1 and S2 in Supplement.

$\mathrm{EF}_{\mathrm{PM}}$ is an important parameter in the compilation of emission inventories for on-road and non-road diesel vehicles in China. However, the foundational work towards quantifying $\mathrm{EF}_{\mathrm{PM}}$ is relatively weak and contains large uncertainties (Huang et al., 2011). Most of the $\mathrm{EF}_{\mathrm{PM}}$ from trucks has been measured by using tunnel and dynamometer tests, which cannot be used to evaluate influential factors for realworld PM emissions from a single truck (Alves et al., 2015b; Mancilla and Mendoza, 2012; Pio et al., 2013; Pietikainen et al., 2015). Although several studies have measured realworld PM emissions from trucks by using on-board tests (Wu et al., 2016, 2015; Zhang et al., 2015), the data should be updated frequently (Huo et al., 2012) because $\mathrm{EF}_{\mathrm{PM}}$ emitted from trucks could change along with improved emission standards. In addition, data of real-world EFPM emitted from non-road diesel vehicles are scarce in China. In 2014, the Ministry of Environmental Protection of the People's Republic of China issued a report titled "Technical guide for the preparation of a single source emission inventory of atmospheric fine particulate matter". However, no measured data of $\mathrm{EF}_{\mathrm{PM}}$ for non-road vehicles are referred in this technical guide, particularly for construction machinery $\left(6 \mathrm{~g} \mathrm{~km}^{-1}\right.$ was predicted for uncontrolled standards) (MEPPRC, 2014). 
Table 1. Specifications of tested excavators and trucks.

\begin{tabular}{llllrrrrr}
\hline ID & Manufacturers & $\begin{array}{l}\text { Model } \\
\text { years }\end{array}$ & $\begin{array}{l}\text { Emission } \\
\text { standards }\end{array}$ & Powers & $\begin{array}{r}\text { Total } \\
\text { weights } \\
(\mathrm{kg})\end{array}$ & $\begin{array}{r}\text { Displacements } \\
(\mathrm{kw})\end{array}$ & $\begin{array}{r}\text { Working } \\
\text { hours } \\
(\mathrm{h})\end{array}$ & $\begin{array}{r}\text { Mileage } \\
(\mathrm{L})\end{array}$ \\
\hline E1 & Volvo & 2013 & stage 2 & 169 & 30500 & 7.1 & 2751 & $/$ \\
E2 & Hitachi & 2007 & pre-stage 1 & 162 & 30200 & 9.8 & 16166 & $/$ \\
E3 & Sany & 2012 & stage 2 & 128 & 22900 & $/$ & 5598 & $/$ \\
E4 & Doosan & 2004 & pre-stage 1 & 110 & 22000 & 8.1 & 12000 & $/$ \\
E5 & Doosan & 2007 & pre-stage 1 & 40 & 5250 & 2.8 & $/$ & $/$ \\
E6 & Komatsu & 2013 & stage 2 & 35 & 5300 & 2.4 & 780 & $/$ \\
T1 & Futian & 2010 & China III & 68 & 4495 & 2.6 & $/$ & 100238 \\
T2 & JAC & 2014 & China IV & 88 & 4495 & 2.8 & $/$ & $/$ \\
T3 & Futian & 2011 & China III & 70 & 11190 & 3.9 & $/$ & 99000 \\
T4 & Chunlan & 2002 & China II & 125 & 15480 & $/$ & $/$ & $/$ \\
T5 & JAC & 2011 & China III & 105 & 15590 & 4.3 & $/$ & 130000 \\
\hline
\end{tabular}

/ indicates no data in GB 252-2015.

Thus far, only one study in China, by Fu et al. (2012), provided $\mathrm{EF}_{\mathrm{PM}}$ of 12 excavators using a portable emission measurement system (PEMS) under different operation modes. On-board measurements need to be expanded to improve the localization of $\mathrm{EF}_{\mathrm{PM}}$ for non-road diesel vehicles in China as soon as possible owing to the complexity of real-world conditions, including the lagging diesel quality and changing emission standards.

Analysis of the chemical composition of PM is essential for source apportionment, human health, and climate change studies. Primary PM emitted from diesel vehicles contains a variety of chemical components including organic carbon (OC), elemental carbon (EC), water-soluble ions (WSIs), elements, and organic species such as n-alkanes, polycyclic aromatic hydrocarbons (PAHs), and hopanes and steranes). Several previous field studies have focused on the chemical composition of PM emitted from diesel vehicles; however, specific characteristics of PM emitted from diesel vehicles and its composition are still largely unknown, particularly for organic compounds. Zhang et al. (2015) characterized $\mathrm{PM}_{2.5}$ compositions (OC, EC, WSIs, and elements) emitted from heavy-duty diesel trucks (HDDTs). Wu et al. (2016) reported the detailed chemical composition of $\mathrm{PM}_{2.5}$ emitted from China III and China IV diesel trucks, including the OC, EC, WSIs, and element contents. In 2012, Fu et al. (2012) were the first to test 12 excavators using on-board test in China, although only the optically based $\mathrm{EF}_{\mathrm{PM}}$ was given.

In this study, PM emitted from on-road and non-road diesel vehicles was measured to (i) test the real-world $\mathrm{EF}_{\mathrm{PM}}$ for excavators and trucks, (ii) identify influential factors on the emitted PM and its composition, and (iii) characterize the chemical components present in the emitted PM. Although the study results required substantial effort, they provide valuable information for developing effective control policies to reduce PM emissions from excavators and trucks.

\section{Experimental}

\subsection{Diesel vehicle and operation mode selection}

In this study, six excavators and five trucks were selected to cover a wide range of emission standards, manufacturers, and engine loads. Detailed information for the selected excavators and trucks is shown in Table 1. As shown in Fig. S2, the increase in the annual production of excavators, from 70000 to 85000 , did not change substantially between 2007 and 2009, when the stage 1 non-road vehicle emission standard was implemented. Therefore, excavators produced during pre-stage 1 and stage 2 emission standards were chosen for this study. On the basis of the China national standard (SEPA and SAQSIQ, 2007), excavators are divided into five types according to their power rating. The excavators in this study were categorized into three types, low $(0-75 \mathrm{kw})$, medium (75-130 kw), or high (130-560 kw) power, under different emission standards. Three operational modes were selected for the excavators to reflect actual use conditions, such as idling, moving, and working. Further descriptions of these three modes can be found in Fu et al. (2012). In addition, consistent sampling times for the different modes were not strictly required in this study as long as sufficient amounts of PM were collected to conduct the subsequent chemical analysis. The average sampling times during idling, moving, and working were 41.7, 24.0, and $28.5 \mathrm{~min}$, respectively.

Three types of diesel trucks were selected in this study, including one China II standards truck, three China III standards trucks, and one China IV standards truck. The China III trucks included one of each light-duty, medium-duty, and heavy-duty diesel truck. On the basis of the traffic rules and driving conditions for on-road diesel trucks, routes were predesigned for the test trucks in Yantai, Shandong province, China (Fig. 1). Because different trucks drive on different 

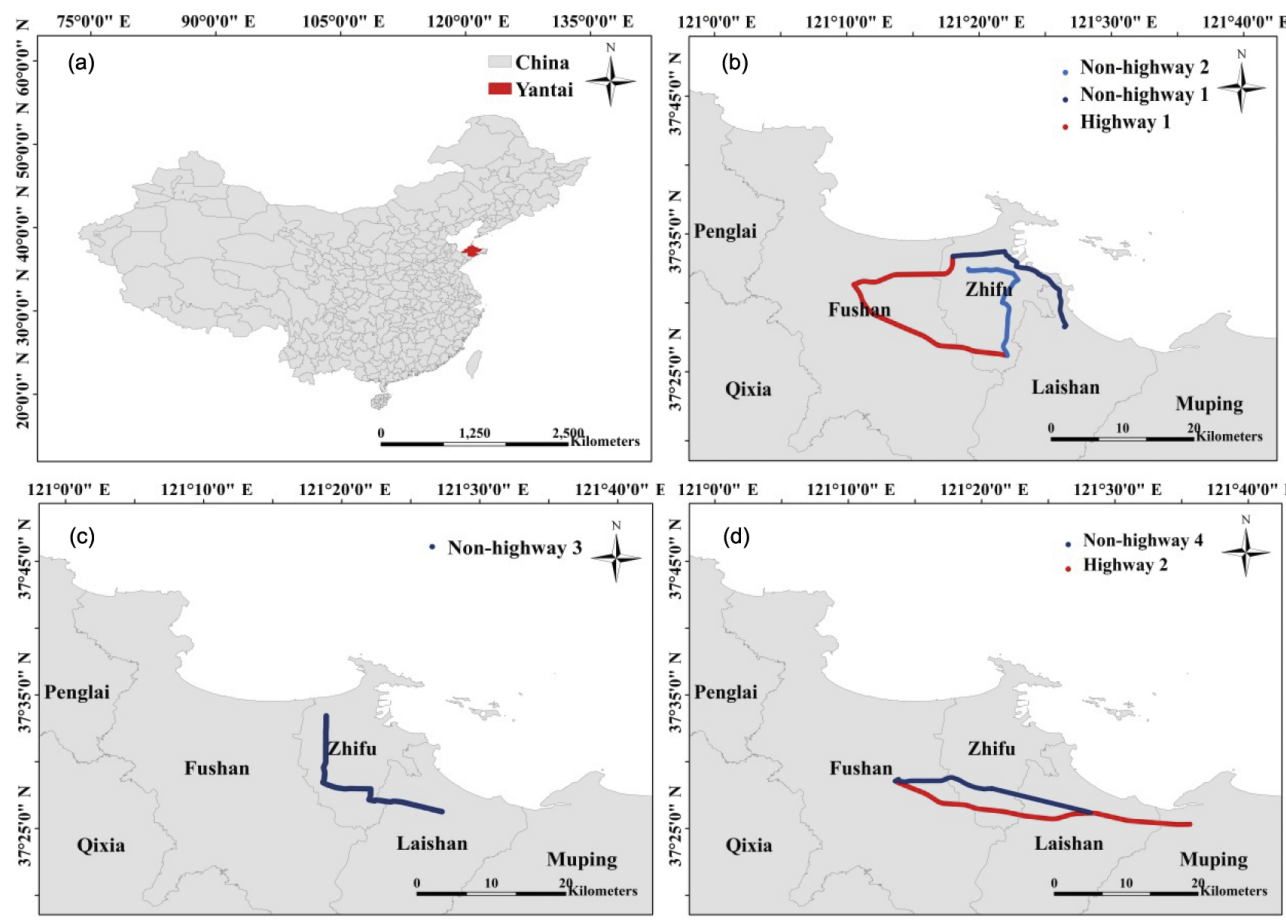

Figure 1. The routes for diesel trucks: (a) site of Yantai; (b) route for China III and China IV light-duty diesel trucks; (c) route for China II heavy-duty diesel truck; (d) route for China III medium-duty and heavy-duty trucks.

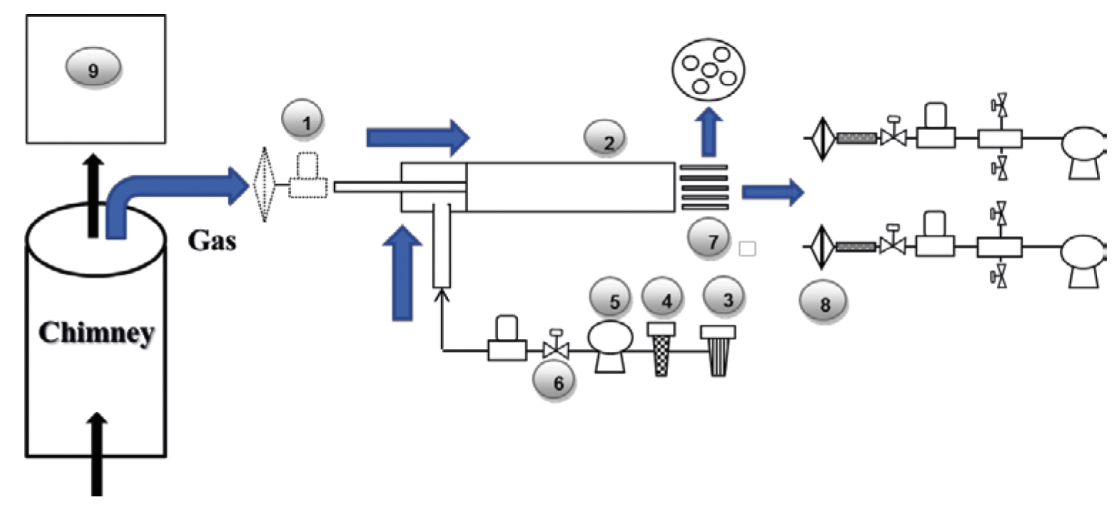

Figure 2. Particulate matter sampling system: 1 is the flowmeter; 2 is the dilute tunnel; 3 is the filter; 4 is the activated carbon; 5 is the fan; 6 is the valve; 7 is the flow divider; 8 is the filter membrane sampler; 9 is the exhaust analyzer.

routes, the selected routes in this study were divided into non-highway and highway categories. The selected routes for China III and China IV light-duty trucks included nonhighway 1, non-highway 2, and highway 1 at lengths of 19 , 35 , and $17 \mathrm{~km}$, respectively. The route chosen for the China II heavy-duty truck (yellow label) was non-highway 3 , at length of $25 \mathrm{~km}$. The routes chosen for China III medium-duty and heavy-duty trucks included non-highway 4 and highway 2 at lengths of 47 and $23 \mathrm{~km}$, respectively. The detailed velocity and road grade information for all of the tested routes are shown in Figs. S3 and S4. Although repeated tests were conducted for some vehicles, it should be noted that only one set of integral data was selected for further discussion owing to incomplete monitoring data (e.g., the data of $\mathrm{CO}_{2}$ and CO concentrations missing). As shown in Tables S3 and S4, the variability for the same operation mode was considered to be acceptable. Some actions were required to reduce the uncertainty. For example, we combined sampling filters for the repeated experiments for $\mathrm{T} 1$ and $\mathrm{T} 3$ to conduct organic compound analysis.

\subsection{On-board emission measurement system}

The on-board emission measurement system was designed and constructed by our research group (Fig. 2). A descrip- 
Table 2. Diesel contents from excavators.

\begin{tabular}{lrrrrrrr}
\hline ID & E1 & E2 & E3 & E4 & E5 & E6 & GB 252-2015 \\
\hline Gross thermal value $\left(\mathrm{MJ} \mathrm{kg}^{-1}\right)$ & 45.1 & 45.1 & 45.3 & 45.3 & 45.3 & 45.3 & $/$ \\
Net thermal value $\left(\mathrm{MJ} \mathrm{kg}^{-1}\right)$ & 42.4 & 42.4 & 42.7 & 42.8 & 42.6 & 42.5 & $/$ \\
Kinematic viscosity $\left(20^{\circ} \mathrm{C}\right)\left(\mathrm{mm}^{2} \mathrm{~s}^{-1}\right)$ & 4.23 & 4.23 & 3.89 & 4.16 & 4.60 & 4.39 & $3.00-8.00$ \\
Moisture (\%) & nd & nd & nd & nd & nd & nd & $/$ \\
Ash content $(\%)$ & 0.04 & 0.04 & 0.05 & 4.16 & 0.03 & 0.05 & $0-0.01$ \\
$\mathrm{C}(\%)$ & 86.3 & 86.3 & 86.4 & 86.8 & 85.9 & 85.9 & $/$ \\
$\mathrm{H}(\%)$ & 11.6 & 11.6 & 11.5 & 11.2 & 12.0 & 12.1 & $/$ \\
$\mathrm{O}(\%)$ & 1.99 & 1.99 & 2.01 & 1.85 & 2.07 & 1.86 & $/$ \\
$\mathrm{N}(\%)$ & 0.05 & 0.05 & 0.05 & 0.04 & 0.06 & 0.05 & $/$ \\
$\mathrm{S}(\mathrm{ppm})$ & 400 & 400 & 700 & 1100 & 200 & 200 & $<350$ \\
\hline
\end{tabular}

nd: not detected. /: no data in GB 252-2015.

tion of the on-board emissions test system was given in our previous report (Zhang et al., 2016). Briefly, this system consists of two main components: a Photon II analyzer, which was used to analyze the flue gas $\left(\mathrm{HC}, \mathrm{CO}, \mathrm{CO}_{2}, \mathrm{SO}_{2}\right.$, and $\mathrm{NO}_{x}$ ), and a PM sampling system (TSP sampler). Although we used TSP sampler to collect PM $\left(D_{\mathrm{p}} \leq 100 \mu \mathrm{m}\right)$ in this study, most of the PM collected in this experiment was considered as fine particles because almost all of the particles emitted from engine combustion are fine (An et al., 2011). The PM sampling system consisted of a dilution system followed by five exhaust channels. Two channels were connected to PM samplers, and the other three were blocked. Before sampling, the emission measurement system was installed on a truck and was connected to the excavator exhaust tube by a stainless steel pipe. This system showed clear improvements over other on-board instruments, such as PEMS and FPS4000 (Zheng et al., 2015); moreover, it has better portability and a stronger ability to collect filter samples for further chemical analysis in the laboratory. The results in this study present the first dataset from on-board measurement of non-road diesel vehicle exhaust in China.

\subsection{Chemical analysis}

\subsubsection{Fuel quality analysis}

Fuel quality has a significant effect on PM emissions from vehicles (Cui et al., 2016; Liang et al., 2005; Zhang and Balasubramanian, 2014). Because various fuels are used in excavators and always have poor qualities, all of the corresponding fuels from each of the tested excavators were collected for quality analysis. The results are given in Table 2. A comparing of the diesel quality used in this study with the standards for non-road vehicles (GB 252-2015) (SEPA and SAQSIQ, 2015) revealed that the sulfur content in most types of diesel used in this study (200-1100 ppm) were higher than allowed by GB 252-2015 ( $<350$ ppm). Additionally, the sulfur content in the diesel used by E4 was $1100 \mathrm{ppm}$, which is significantly higher than that used in the other excavators.
Furthermore, the ash content of the diesel used by E4 was $4.16 \%$, which is about 420 times than the limit given by GB 252-2015.

\subsubsection{PM and chemical composition analysis}

Quartz-fiber filters were used to collect PM samples for PM weight measurement and chemical analysis; the weight losses of these filters were neglected through strict sampling processes. All of the filters were weighed before and after sampling to determine the PM mass concentrations. Before each measurement, the filters were balanced at $25^{\circ} \mathrm{C}$ and $40 \%$ relative humidity for $24 \mathrm{~h}$. Each filter was weighed three times. WSIs were analyzed using ion chromatography (Dionex ICS3000, Dionex Ltd., Sunnyvale, California, United States) following the method of Cui et al. (2016). Elements analysis was performed using inductively coupled plasma mass spectrometry (ICP-MS; ELAN DRC II type, Perkin Elmer Ltd., Hong Kong) (Cui et al., 2016).

Because the organic compounds on the filters were insufficient for quantification, we merged filters of different operation modes or driving routes based on the proportion of sampling time during each mode or route for analyzing the PM characteristic for each diesel vehicle. Quartz filter samples were spiked with internal standards (including acenaphthene- $d_{10}$, benzo[a]anthracene- $d_{12}$, pyrene- $d_{10}$, coronene- $d_{12}$, cholestane- $d_{4}, \mathrm{n}-\mathrm{C} 15-d_{32}, \mathrm{n}-\mathrm{C} 20-d_{42}, \mathrm{n}-\mathrm{C} 24-$ $\left.d_{50}, \mathrm{n}-\mathrm{C} 30-d_{58}, \mathrm{n}-\mathrm{C} 32-d_{66}, \mathrm{n}-\mathrm{C} 36-d_{74}\right)$ and were ultrasonically extracted twice in $30 \mathrm{~mL}$ of a $1: 1$ mixture of hexane and dichloromethane for $10 \mathrm{~min}$. All extracts from each sample were combined, filtered, and concentrated to approximately $0.5 \mathrm{~mL}$.

Organic species including n-alkanes, PAHs, and hopanes and steranes were analyzed using GC-MS (Agilent 7890A GC-5975C MS) with a DB-5MS column of $30 \mathrm{~m}$ in length, an inner diameter of $0.25 \mathrm{~mm}$, and thickness of $0.25 \mu \mathrm{m}$. The following GC operating program was used: $60^{\circ} \mathrm{C}$ for $4 \mathrm{~min}$, then increase $5^{\circ} \mathrm{min}^{-1}$ to $150^{\circ} \mathrm{C}$ with $2 \mathrm{~min}$ static time, and finally increase $3{ }^{\circ} \mathrm{Cmin}^{-1}$ to $306^{\circ} \mathrm{C}$ with a $20 \mathrm{~min}$ static 
time. The GC had an injector temperature of $290^{\circ} \mathrm{C}$, an injector volume of $2 \mu \mathrm{L}$, He carrier gas, and a gas flow rate of $1.2 \mathrm{mLmin}^{-1}$. The electron impact (EI) mode at $70 \mathrm{eV}$ and selected-ion-monitoring (SIM) mode were selected to determine the concentrations of PAHs, hopanes, and steranes. For organic matter, blank samples and recovery rates (66.7-128\% for five surrogates) were measured. The blank concentrations were subtracted from the sample concentrations. The final concentrations of organic matters were not corrected for the recoveries.

The PM chemical constituents analyzed in this study were OC; $\mathrm{EC}$; WSIs including $\mathrm{SO}_{4}^{2-}, \mathrm{NO}_{3}^{-}, \mathrm{Cl}^{-}$, and $\mathrm{NH}_{4}^{+}$; elements including $\mathrm{Na}, \mathrm{Mg}, \mathrm{K}, \mathrm{Ca}, \mathrm{Ti}, \mathrm{V}, \mathrm{Cr}, \mathrm{Mn}, \mathrm{Fe}, \mathrm{Co}$, $\mathrm{Ni}, \mathrm{Cu}, \mathrm{Zn}$, and $\mathrm{Pb}$; n-alkanes including $\mathrm{C} 12$ to $\mathrm{C} 40$; the 16 USEPA priority PAHs including naphthalene (Nap), acenaphthylene (Acy), acenaphthene (Ace), fluorene (Flu), phenanthrene (Phe), anthracene (Ant), fluoranthene (Fluo), pyrene (Pyr), benzo [a]anthracene (BaA), chrysene (Chry), benzo[b]fluoranthene $(\mathrm{BbF})$, benzo[k]fluoranthene $(\mathrm{BkF})$, benzo[a]pyrene (BaP), indeno[1,2,3-cd]pyrene (IcdP), dibenz[a,h]anthracene (DahA), and benzo[ghi]perylene (BghiP); hopanes and steranes including ABB-20R-C27cholestane (ABB), AAA-20S-C27-cholestane (AAA), $17 \mathrm{~A}(\mathrm{H})-22,29,30$-trisnorhopane $(\mathrm{Tm}), 17 \mathrm{~A}(\mathrm{H})-21 \mathrm{~B}(\mathrm{H})-30-$ norhopane (30AB), and $17 \mathrm{~A}(\mathrm{H})-21 \mathrm{~B}(\mathrm{H})$-hopane (29AB).

\subsection{Data processing}

\subsubsection{Fuel-based emission factors}

Fuel-based emission factors were calculated using the carbon mass balance formula:

$\mathrm{EF}_{i}=\frac{\Delta X_{i}}{\Delta \mathrm{CO}_{2}} \cdot \frac{M_{i}}{M_{\mathrm{CO}_{2}}} \cdot \mathrm{EF}_{\mathrm{CO}_{2}}$,

where $\mathrm{EF}_{i}$ and $\mathrm{EF}_{\mathrm{CO}_{2}}\left(\mathrm{~g} \mathrm{~kg}^{-1}\right.$ fuel) are the emission factors for species $i$ and $\mathrm{CO}_{2}$, respectively; $\Delta X_{i}$ and $\Delta \mathrm{CO}_{2}$ $\left(\mathrm{mol} \mathrm{m}^{-3}\right)$ are the background-corrected concentrations of species $i$ and $\mathrm{CO}_{2}$, respectively; and $M_{i}$ and $M_{\mathrm{CO}_{2}}\left(\mathrm{~g} \mathrm{~mol}^{-1}\right)$ represent the molecular weights of species $i$ and $\mathrm{CO}_{2}$, respectively.

The $\mathrm{CO}_{2}$ emission factors $\left(\mathrm{EF}_{\mathrm{CO}_{2}}\right)$ were calculated as

$\mathrm{EF}_{\mathrm{CO}_{2}}=R_{\mathrm{FG}} \cdot c\left(\mathrm{CO}_{2}\right) \cdot M_{\mathrm{CO}_{2}}$,

where $c\left(\mathrm{CO}_{2}\right)\left(\mathrm{mol} \mathrm{m}^{-3}\right)$ is the molar concentration of $\mathrm{CO}_{2}$, and $R_{\mathrm{FG}}\left(\mathrm{m}^{3} \mathrm{~kg}^{-1}\right.$ fuel) represents the flue gas emission rate.

The flue gas emission rate was calculated as

$R_{\mathrm{FG}}=\frac{C_{F}}{c\left(C_{\mathrm{CO}}\right)+c\left(C_{\mathrm{CO}_{2}}\right)+c\left(C_{\mathrm{PM}}\right)}$,

where $C_{F}\left(\mathrm{~g} \mathrm{C} \mathrm{kg}^{-1}\right.$ fuel) represents the mass of carbon in $1 \mathrm{~kg}$ diesel fuel, and $c\left(C_{\mathrm{CO}}\right), c\left(C_{\mathrm{CO}_{2}}\right)$, and $c\left(C_{\mathrm{PM}}\right)\left(\mathrm{g} \mathrm{Cm}^{-3}\right)$ represent the flue gas mass concentrations of carbon as $\mathrm{CO}$, $\mathrm{CO}_{2}$, and $\mathrm{PM}$, respectively.

\subsubsection{Average fuel-based emission factors for excavators and trucks}

The average fuel-based emission factor for each excavator in each relevant operation mode was calculated as

$\mathrm{EF}_{i, j}=\sum \mathrm{EF}_{i, j, g} \cdot P_{j, g}$,

where $\mathrm{EF}_{i, j}\left(\mathrm{~g} \mathrm{~kg}^{-1}\right.$ fuel) is the average emission factor of species $i$ from excavator $j, \mathrm{EF}_{i, j, g}\left(\mathrm{~g} \mathrm{~kg}^{-1}\right.$ fuel) is the emission factor of species $i$ from excavator $j$ in mode $g$, and $P_{j, g}$ $(\%)$ is the proportion of activity time (Fu et al., 2012) for excavator $j$ in mode $g$.

The average fuel-based emission factor for each truck in different driving conditions was calculated as

$\mathrm{EF}_{i, j}=\sum \mathrm{EF}_{i, j, s} \cdot P_{j, s}$,

where $\mathrm{EF}_{i, j}\left(\mathrm{~g} \mathrm{~kg}^{-1}\right.$ fuel $)$ is the average emission factor for species $i$ from truck $j, \mathrm{EF}_{i, j, s}\left(\mathrm{~g} \mathrm{~kg}^{-1}\right.$ fuel) is the emission factor of species $i$ for truck $j$ in driving condition $s$, and $P_{j, s}$ $(\%)$ is the proportion of activity time for truck $j$ in driving condition $s$.

\subsubsection{Benzo[a]pyrene equivalent concentration $\left(\mathrm{BaP}_{\mathrm{eq}}\right)$}

The various PAHs have a wide range of carcinogenic risks. Therefore, it is not accurate to evaluate the harmful effects of PAHs on human health using the total combined mass concentration. Instead, $\mathrm{BaP}_{\mathrm{eq}}$ is typically used to evaluate the carcinogenic risks associated with individual PAH (Mirante et al., 2013), which is calculated as

$\mathrm{BaP}_{\mathrm{eq}}=\sum \mathrm{PAH}_{i} \cdot \mathrm{PEF}$,

where $\mathrm{PAH}_{i}$ is the measured concentration of an individual PAH for excavator $i$, and PEF is the potency equivalence factor for that PAH obtained from Wang et al. (2008).

\section{Results and discussion}

\subsection{Fuel-based PM emission factors for excavator exhaust}

The $\mathrm{EF}_{\mathrm{PM}}$ values for excavator exhaust are illustrated in Fig. 3, with detailed information given in Table S5. The maximum $\mathrm{EF}_{\mathrm{PM}}$ was 37 times than the minimum value. In general, the average $\mathrm{EF}_{\mathrm{PM}}$ for different excavators ranged from 96.5 to $2323 \mathrm{mg} \mathrm{kg}^{-1}$ fuel, with an average of $829 \pm$ $806 \mathrm{mg} \mathrm{kg}^{-1}$ fuel. The EFPM values of the excavators reported by Fu et al. (2012) are within the range of $\mathrm{EF}_{\mathrm{PM}}$ values in this study. The wide range of $\mathrm{EF}_{\mathrm{PM}}$ values here could be attributed to differences in emission standards for the excavators. Those tested by Fu et al. (2012) included stage 1 and stage 2 emission standards, whereas the excavators in this 

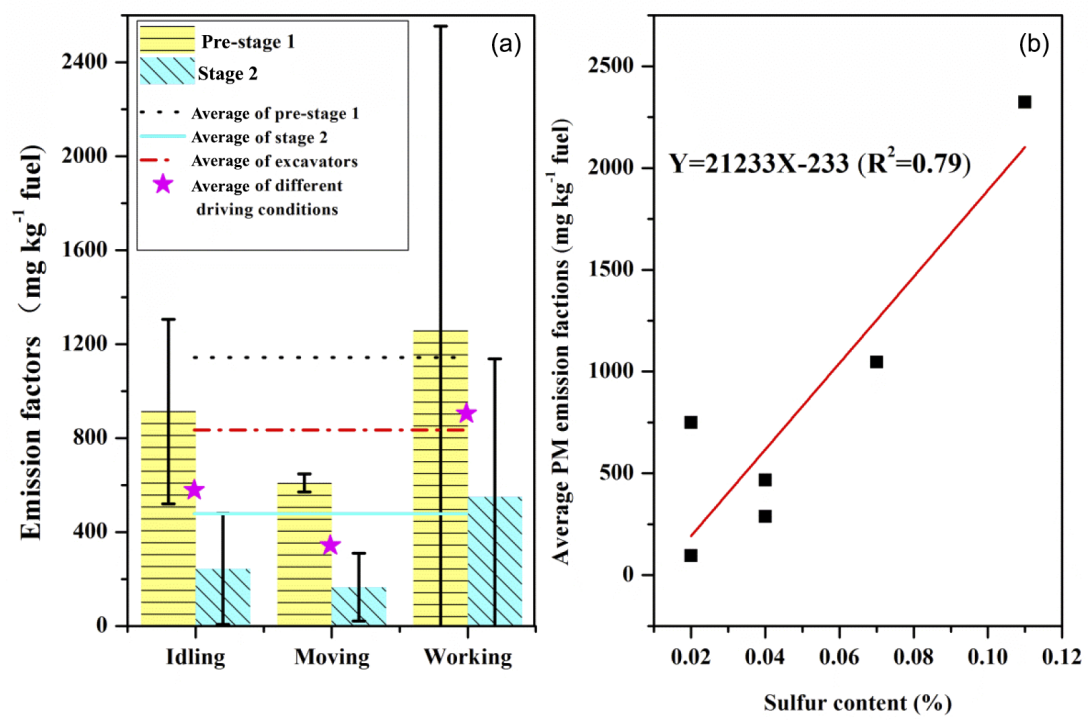

Figure 3. $\mathrm{EF}_{\mathrm{PM}}$ for excavators with different operational modes and emission standards (a) and the correlation with sulfur contents (b).

study were used with the emissions standards of pre-stage 1 and stage 2 .

The EFPM measured for pre-stage 1 excavators during idling, moving, and working were $914 \pm 393,609 \pm 38$, and $1258 \pm 1295 \mathrm{mg} \mathrm{kg}^{-1}$ fuel, respectively, whereas those for stage 2 excavators were $243 \pm 236,165 \pm 144$, and $551 \pm$ $587 \mathrm{mg} \mathrm{kg}^{-1}$ fuel, respectively. That is, the EFPM for the stage 2 excavators under idling, moving, and working modes was reduced by 73,73 , and $56 \%$ compared with the prestage 1 excavator, respectively, and the average $\mathrm{EF}_{\mathrm{PM}}$ for the excavator decreased by $58 \%$ from pre-stage 1 to stage 2 . $\mathrm{EF}_{\mathrm{PM}}$ can be influenced by many factors. In this study, the $\mathrm{EF}_{\mathrm{PM}}$ for excavators with different power ratings ranged from $96.5(35 \mathrm{kw})$ to $2323(110 \mathrm{kw}) \mathrm{mg} \mathrm{kg}^{-1}$ fuel; however, the correlations between EFPM and engine power (Fig. S5) were weak. Additionally, fuel quality, emission standards, and operation mode significantly influenced the EFPM. Given that there is no government supervision of diesel used for non-road vehicles, the reduction in average $\mathrm{EF}_{\mathrm{PM}}$ from prestage 1 to stage 2 could be attribute mainly to both the different emission standards and diesel quality. As shown in Table S5, the average EFPM from E5 to E6 with the same fuel quality but different emission standards was reduced $87.1 \%$. Similarly, EFPM was reduced $38.2 \%$ from E2 to E1, which indicates that emission standards have significant impacts on

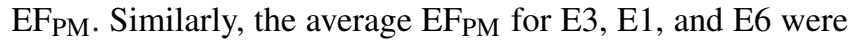
under the same emission standard decreased with improvement in fuel quality, which suggests the influence of diesel quality. As shown in Fig. 3, good correlation $\left(R^{2}=0.79\right.$, $P<0.01$ ) was found between the average EFPM for excavators and sulfur contents in fuels, which is consistent with the results reported by Yu and Yang (2007). Furthermore, the $\mathrm{EF}_{\mathrm{PM}}$ for the various excavators varied significantly under



Figure 4. Diesel trucks EFPM for different emission standards (a), vehicle sizes (b), and driving conditions (c).

different operation modes. Specifically, working excavators exhibited the highest $\mathrm{EF}_{\mathrm{PM}}$, which was more than double the values for idling and moving excavators. The average $\mathrm{EF}_{\mathrm{PM}}$ for excavators was $578 \pm 467$ while idling, $343 \pm 264$ while moving, and $904 \pm 979 \mathrm{mg} \mathrm{kg}^{-1}$ fuel while working. Excavators under the working mode produced the highest average $\mathrm{EF}_{\mathrm{PM}}$, which might be ascribed to the higher engine load causing a lower air-fuel ratio. 


\subsection{Fuel-based PM emission factor for trucks}

The $\mathrm{EF}_{\mathrm{PM}}$ for all measured trucks varied from 176 to $951 \mathrm{mg} \mathrm{kg}^{-1}$ fuel. The maximum $\mathrm{EF}_{\mathrm{PM}}$ for trucks was 5 times larger than the minimum value. The average $\mathrm{EF}_{\mathrm{PM}}$ for the tested diesel trucks was $498 \pm 234 \mathrm{mg} \mathrm{kg}^{-1}$ fuel, which is consistent with that reported by $\mathrm{Wu}$ et al. (2016) (range: 95.6-1147 $\mathrm{mg} \mathrm{kg}^{-1}$ fuel; average: $427 \mathrm{mg} \mathrm{kg}^{-1}$ fuel). The average real-world $\mathrm{EF}_{\mathrm{PM}}$ values of diesel trucks with different emission standards, vehicle sizes, and driving patterns are given in Fig. 4. The measured EFPM for China II, China III, and China IV diesel trucks varied from 200 to $548 \mathrm{mg} \mathrm{kg}^{-1}$ fuel. The EFPM for the China II truck measured in this study is lower than that reported by Liu et al. (2009) (910$2100 \mathrm{mg} \mathrm{kg}^{-1}$ fuel). The average $\mathrm{EF}_{\mathrm{PM}}$ values for light-duty, medium-duty, and heavy-duty diesel trucks were $524 \pm 457$, 459 , and $492 \mathrm{~m} \mathrm{~kg}^{-1}$ fuel, respectively. The average $\mathrm{EF}_{\mathrm{PM}}$ values for trucks under non-highway and highway driving patterns were $548 \pm 311$ and $497 \pm 231 \mathrm{mg} \mathrm{kg}^{-1}$ fuel, respectively. As shown in Fig. 4, reductions of $\mathrm{EF}_{\mathrm{PM}}$ from the China II to China IV trucks, and those from the China III to China IV trucks were 63.5 and $65.6 \%$, respectively. The diesel used for trucks was assumed to be identical in quality owing to strict diesel quality regulations for on-road trucks. Therefore, the reductions of $\mathrm{EF}_{\mathrm{PM}}$ for different trucks could be attributed mainly to the improvements in emission standards. Of particular note was that the $\mathrm{EF}_{\mathrm{PM}}$ values for China III and light-duty diesel trucks were higher than those for the other corresponding trucks. The reason might be the results of poor driving conditions, i.e., low average speed and highly varied speed (Figs. S3 and S4). The same tendency is shown in Fig. 4, in which diesel trucks driving on non-highways (average speed of $28.5 \mathrm{~km} \mathrm{~h}^{-1}$ ) emitted more PM than those driving on highways (average speed of $60.7 \mathrm{~km} \mathrm{~h}^{-1}$ ). The road grade further affected the $\mathrm{EF}_{\mathrm{PM}}$ of the on-road diesel trucks. For example, the $\mathrm{EF}_{\mathrm{PM}}$ for T5 driving on highways was lower than that for $\mathrm{T} 1$ driving on highways owing to the lower road grade for T5 (Fig. S4).

\subsection{Particulate matter composition for individual diesel vehicles}

Four types of constituents were considered for reconstituting the PM mass in this study: (1) organic matter, which was calculated by multiplying the corrected $\mathrm{OC}$ by a factor of 1.6 (Almeida et al., 2006); (2) EC; (3) WSIs; and (4) elements. The reconstituted masses for the excavator samples were $74.7-123 \%$ of the measured mass, whereas the reconstituted masses for the diesel truck samples were only 43.2$54.4 \%$ of the measured mass (Fig. 5). In addition to the uncalculated components, this discrepancy might be attributed to a distribution error between OC and EC by using TOR, droplet effects, or oxides when only metal elements were considered.
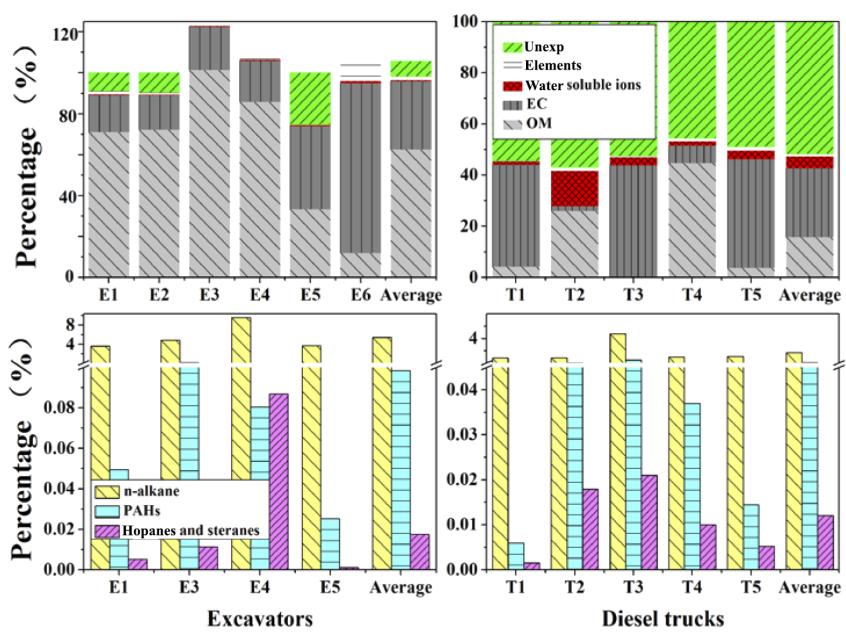

Figure 5. Compositional constituents of PM for individual vehicles $(\%)$.

\subsubsection{Particulate matter composition for individual excavator}

The chemical composition of PM for each excavator is shown in Fig. 5 and Table S6. For each excavator, the carbonaceous component $(\mathrm{OM}+\mathrm{EC})$ was the dominant species. This is consistent with results of a previous study by Liu et al. (2005), who reported that the proportions of OC and EC in PM ranged from 70 to $91 \%$ (Liu et al., 2005). Because the OC / EC ratio is also used to identify the source of atmospheric particulate pollution, further assessment was performed on these ratios in different operation modes for each excavator (Fig. 6). The average OC / EC ratios during idling, moving, and working were 1.57, 0.57, and 2.38, respectively. The OC / EC ratio during idling was higher than 1 because soot is rarely generated at low temperatures and fuel-rich zones. These results are also consistent with those of Liu et al. (2005). Furthermore, Liu et al. (2005) reported that the OC / EC ratios decreased with an increase in load for non-road engines. Although the trend of OC / EC ratios from idling (low load) to moving (medium load) are consistent with those reported by Liu et al. (2005), the OC / EC ratio under working (high load) was higher than those under idling and moving, which agrees with the results reported by Zhang and Balasubramanian (2014). As shown in Fig. 6, the differences between the OC / EC ratios for different excavator operation modes were significant and could have been affected by numerous factors such as transient working conditions, diesel sulfur content, and extensive OC sources (Cocker et al., 2004; Liu et al., 2005; Ruiz et al., 2015).

As shown in Fig. 5, the WSIs and element fractions ranged from 0.335 to $1.21 \%$ and from 0.163 to $7.50 \%$, respectively, for all excavators. The total proportion of WSIs and elements to PM was the highest in excavator E6, followed by excavator E1. Generally, the total proportion of WSIs and elements to 

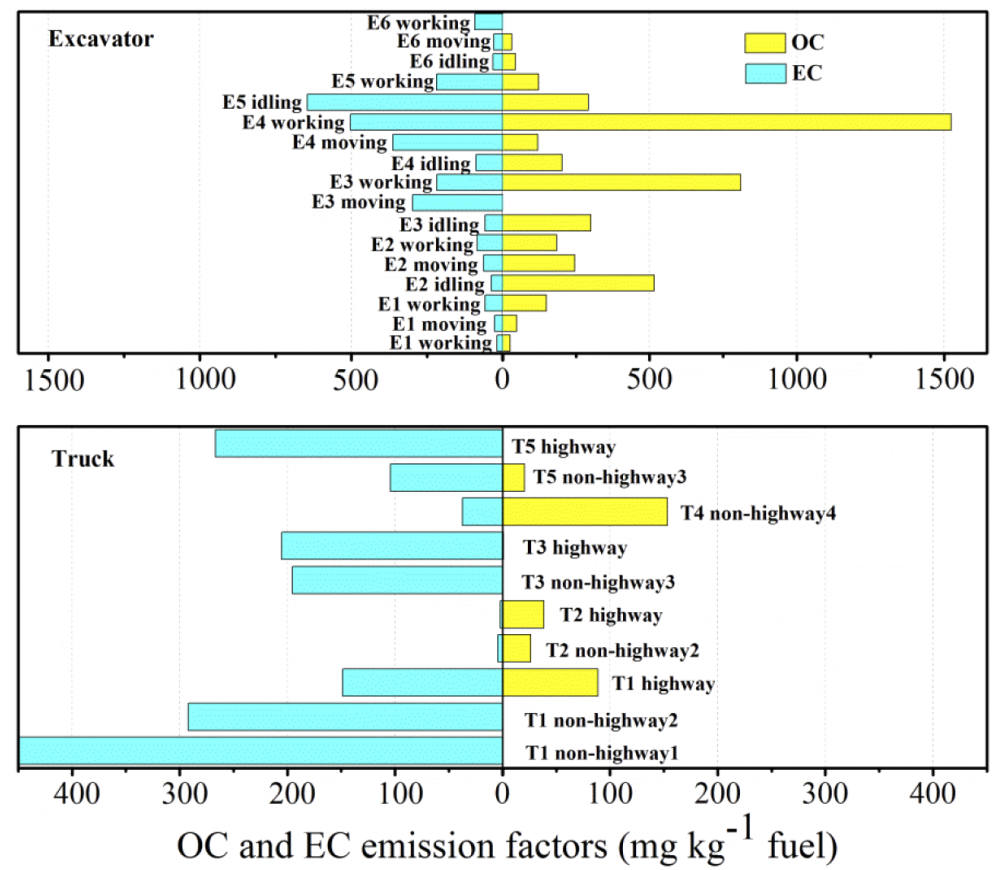

Figure 6. OC / EC ratios in different operational modes and driving conditions for excavators and trucks.

PM in the exhaust from excavator E6 was 4 to 14 times than the corresponding proportions in the exhaust from the other excavators. Sulfate and nitrate were the main WSIs (79.1$90.0 \%$ of WSIs) for almost all of the excavators, except for $\mathrm{E} 1$, in which the proportion of $\mathrm{Cl}^{-}(67.2 \%)$ was the highest (Table $\mathrm{S6}$ ). $\mathrm{Fe}, \mathrm{Ca}, \mathrm{Na}, \mathrm{Mg}$, and $\mathrm{K}$ were the relatively dominant elements, except for $\mathrm{E} 4$, which showed $\mathrm{Fe}, \mathrm{Zn}$, and $\mathrm{Cu}$ as the most abundant elements. Wang et al. (2003) reported that the concentrations of the crustal elements $\mathrm{Fe}, \mathrm{Ca}$, and $\mathrm{Mg}$ accounted for $50 \%$ of the total elements in diesel fuel, which was significantly higher than anthropogenic elements emitted from diesel vehicle engines. This result is consistent with the results of our study. Similarly, we supposed that diesel was the dominant source for these elements because the sampling tube was placed directly on the tailpipe. In addition, $\mathrm{Zn}$ and $\mathrm{Cu}$ were also abundant elements for $\mathrm{E} 4$, which was different from other excavators. Lin et al. (2015) found that $\mathrm{Zn}$ and $\mathrm{Cu}$ originated from lubricating oil except for that used in brake linings. Therefore, we supposed that diesel and lubricating oil combustion were likely the main sources of the elements emitted from E4 (produced in 2004). Furthermore, the element fractions for the two excavators manufactured in 2013 (1.42\% for E1 and $7.50 \%$ for E6; $4.09 \mathrm{mg} \mathrm{kg}^{-1}$ fuel for E1 and $7.24 \mathrm{mg} \mathrm{kg}^{-1}$ fuel for E6) were higher than those for the other excavators $\left(4.10,1.71,8.73\right.$, and $1.56 \mathrm{mg} \mathrm{kg}^{-1}$ fuel for E2, E3, E4, and E5). This indicates that elements emissions were deteriorating and that more stringent control technology should be developed to avoid adverse health effects from the total element composition of PM in the exhaust.
The n-alkanes, PAHs, and hopanes and steranes fractions in the exhaust from the excavators were 3.6-9.6, 0.03-0.24, and $0.001-0.09 \%$, respectively. Liang et al. (2005) characterized diesel PM emitted from non-road engines using a dynamometer test and found that $\mathrm{n}$-alkanes accounted for $0.83 \%$ of PM, which is lower than the proportion found in this study. This result could be attributed to the lowsulfur diesel fuel and the different sampling methods they used. In contrast to the fractions of WSIs and elements, the fractions of n-alkanes, hopane, and steranes were the highest in excavator E4, whereas the fraction of PAHs was the highest for the exhaust from E3. E4 had poorer diesel quality compared with E3, which could explain high nalkane, hopane, and sterane concentrations. Similarly, Rogge et al. (1993) found that $n$-alkanes, hopane, and steranes were mostly derived from the incomplete combustion of fuel and lubricant oil. However, we speculate that the PAHs in this study were affected by combustion conditions (i.e., combustion temperature) because E3, with the stage 2 standard, had better performance and superior fuel quality. PAH isomer ratios have been widely used to conduct source apportionment for environmental receptors (such as sediments) (Liu et al., 2012). Yunker et al. (2002) found that the ratios of the principal masses of PAH 178, 202, 228, and 276 had the best potential to distinguish between natural and anthropogenic sources. For the excavators, the ranges of the ratios for $\mathrm{BaA} /(\mathrm{BaA}+\mathrm{Chry})$, IcdP / (IcdP + BghiP), and Flua / (Flua + Pry) were 0.26-0.86, 0.20-1.0, and 0.240.87 , respectively, with averages of $0.47 \pm 0.27,0.44 \pm$ 0.38 , and $0.48 \pm 0.27$, respectively (Fig. 7). The average 

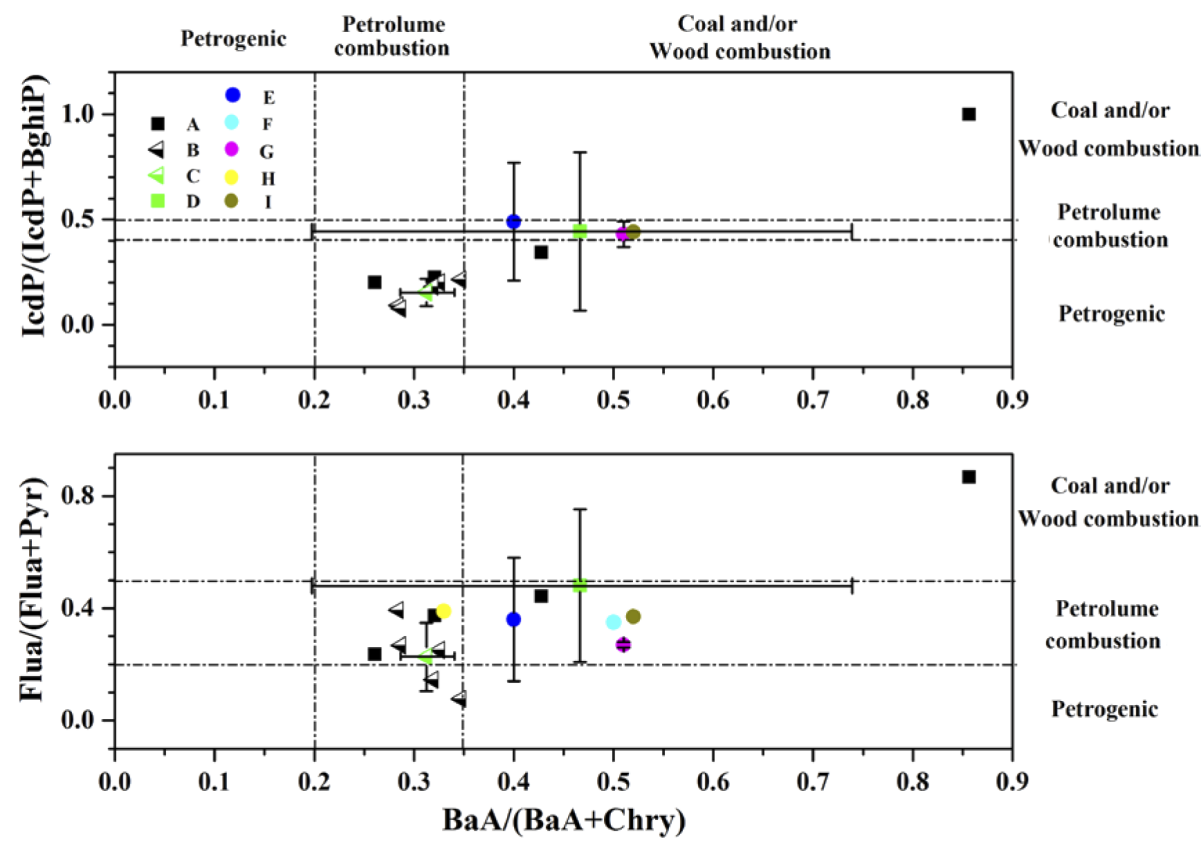

Figure 7. Cross plots for the ratios of $\mathrm{BaA} /(\mathrm{BaA}+\mathrm{Chry})$ vs. IcdP / (IcdP + BghiP) and BaA / (BaA + Chry) vs. Flua / (Flua + Pry) and comparison with those from other diesel vehicle sources. A and B are the isomer ratios of the PAHs from the excavators and trucks, respectively, tested in this study; C and D are the average isomer ratios of PAHs for trucks and excavators tested in this study; E, F, G, H, and I are results obtained from Liu et al. (2015), Wang et al. (2015), Shah et al. (2005), Schauer et al. (1999), and Chen et al. (2013).

ratios of the PAHs in excavator exhaust obtained in this study are similar to those reported by Liu et al. (2015). The E4 excavator showed obvious differences in the ratios of $\mathrm{BaA} /(\mathrm{BaA}+\mathrm{vChry})$, IcdP / (IcdP + BghiP $)$, and Flua / (Flua + Pry) from those for the other excavators. The isomer ratios of $\mathrm{BaA} /(\mathrm{BaA}+\mathrm{Chry}), \mathrm{IcdP} /(\mathrm{IcdP}+\mathrm{BghiP})$, and Flua / (Flua + Pry) for E4 were 0.86, 1.0, and 0.87, respectively, which are different from the ranges for fuel combustion defined by Yunker et al. (2002). The ratios of PAHs emitted from diesel vehicles reported by Yunker et al. (2002) mainly referred those from on-road diesel vehicles. However, the operation mode and fuel quality for non-road diesel vehicles are more complicated than those for on-road diesel vehicles. Therefore, the results obtained in this study could provide references values for the isomer ratios of PAHs in non-road diesel vehicle exhaust.

\subsubsection{Particulate matter composition for individual diesel trucks}

For diesel trucks, the total carbonaceous composition $(\mathrm{OM}+\mathrm{EC})$ accounted for $44.0 \%$ (T1), $27.9 \%$ (T2), $43.9 \%$ (T3), $51.6 \%$ (T4), and $46.3 \%$ (T5) of PM, which are all lower than the values reported in previous studies (Chow et al., 2011; Wu et al., 2015). One of the main reasons is the differences in OC and EC detection methods used in our study. Through a comparison of National Institute for Occupational Safety and Health (NIOSH) and Interagency Monitoring of Protected Visual Environments (IMPROVE) protocols, two common thermal-optical methods of OC and EC analysis for $333 \mathrm{PM}_{2.5}$ samples collected by Cheng et al. (2011), it was found that NIOSH-defined EC was up to $80 \%$ lower than that of defined by IMPROVE. The IMPROVE thermal-optical method was used in this study, which could have caused under-valuation of OC. Except for T2 and T4 trucks, almost all of the OC / EC ratios for diesel trucks calculated in this study were lower than 1 , which is consistent with conclusions from previous studies (Fig. 6). The OC / EC ratios for $\mathrm{T} 2$ during highway and non-highway driving were 5.64 and 15.5, respectively, which might be an effect of the China IV emission standard. A different study also found that modern diesel passenger cars (Euro 4 and Euro 5) had high OC / EC ratios (Alves et al., 2015b). The OC / $\mathrm{EC}$ ratio for T4 while driving on non-highways was 4.10 , which might have been caused by the low driving speed (the driving speed was zero for the first 500s for T4 as shown in Fig. S3). Cheng et al. (2015) reported that the OC / EC ratios were substantially higher than 1 under idling or with low load.

The sum of WSIs and element fractions was lower than $5 \%$ of the PM for all of the diesel trucks except for T2, which is consistent with the results of Zhang et al. (2015). $\mathrm{SO}_{4}^{2-}$ was the most abundant ion for trucks $\mathrm{T} 2$ and $\mathrm{T}$, whereas $\mathrm{NO}_{3}^{-}$was the most abundant ion for trucks $\mathrm{T} 1, \mathrm{~T} 3$, and T4. For T2, WSIs (13.8\%) were the most significant PM component, followed by OC, which was 4-10 times higher than other trucks (Table S6). This occurred likely because $\mathrm{T} 2$ is a China IV diesel vehicle with well-controlled com- 
bustion conditions, which leads to more water emissions, which in turn accelerates the transformation from the gas phase to WSIs (e.g., the transformation of $\mathrm{SO}_{2}$ to $\mathrm{SO}_{4}^{2-}$ ). As shown in Table S6, Fe was the most abundant element for trucks $\mathrm{T} 1$ and $\mathrm{T} 5$, whereas $\mathrm{Ca}$ was the most abundant element for trucks T2, T3, and T4. The total element fraction of T2 (China IV) was 16 times higher than that of T1 (China IIi). Although the $\mathrm{EF}_{\mathrm{PM}}$ for diesel trucks decreased with stricter emission standards, the WSIs and element contents increased. It is well known that sulfate and nitrate are major precursors of acid rain, and elements emitted by diesel engines also have significant adverse health effects on humans. Thus attention needs to be paid to this phenomenon.

The n-alkanes, PAHs, hopane and steranes fractions were $0.85-4.78,0.01-0.54$, and $0.002-0.024 \%$, for the trucks. As shown in Table S6, C20 was the most abundant n-alkane in PM from T1, T2, and T4, whereas that from T3 and T5 was C19. The most abundant species of PAHs was pyrene. Nalkanes, PAHs, hopanes, and steranes accounted for the highest proportions of PM in the exhaust from T3, which might have been affected by many factors, including differences in the engine power rating, complex reactions in the engine (combustion processes and pyrolysis reactions related to temperature, humidity, etc.), and driving conditions. As shown in Fig. 7, the isomer ratios for diesel trucks were $0.28-0.35$ for $\mathrm{BaA} /(\mathrm{BaA}+$ Chry), 0.08-0.22 for IcdP / (IcdP + BghiP), and $0.08-0.39$ for Flua / (Flua + Pry), with averages of $0.31 \pm 0.03,0.15 \pm 0.06$, and $0.23 \pm 0.12$, respectively. These results are similar to those reported by Schauer et al. (1999).

\subsection{Average chemical composition of PM emitted from diesel vehicles}

\subsubsection{Average chemical composition of $\mathrm{PM}$ in excavator exhaust}

The average PM chemical compositions for excavator exhaust are listed in Table 3. Carbonaceous matter was the dominant component, accounting for $72.5 \%$ of the PM for excavators; furthermore, $\mathrm{OC}$ was the most abundant species $(39.2 \%)$ for PM. The total element fraction was the second largest group, contributing $1.76 \%$ of the PM. Of the elements, emissions were dominated by $\mathrm{Fe}$ at $46.3 \%$. In addition, the proportion of n-alkanes in the PM from excavator exhaust $(5.14 \%)$ was higher than that of the other organic matter types (PAHs were $0.098 \%$ while hopane and sterane were $0.026 \%$ ) and $\mathrm{C} 20 / \mathrm{C} 19$ was the most abundant n-alkane. For parent $\mathrm{PAH}$, the emissions were dominated by pyrene and fluoranthene, followed by naphthalene and chrysene.

Table 3 summarizes the average source profiles of PM in excavator exhaust as derived in this study, as well as those previously reported by others for comparison. As shown in Table 3, the average fraction of total carbonaceous components for the excavators tested in this study is consistent with that for a marine engine, whereas the element fraction was lower than that for a marine engine (Sippula et al., 2014). Iron oxide is recognized as a catalyst and can promote soot burnout during combustion processes (Kasper et al., 1999). The EC fraction of PM in the excavator exhaust is higher than that reported by Sippula et al. (2014), which might be the result of a lower metal fraction in the excavators used for their study. The proportion of n-alkanes measured in this study was significantly higher than those emitted from a marine engine (4-fold) and non-road generator (6-fold) in a different study (Liang et al., 2005), which could be the result of different aliphatic compounds in the diesel fuels (Sippula et al., 2014). For the marine engine and non-road generators, $\mathrm{C} 22$ and $\mathrm{C} 17$ were the most abundant n-alkane species. PAHs were dominated by phenanthrene for a marine engine and fluoranthene for non-generators, which is different from the result obtained for the excavators. This indicates that the PM emitted from different types of non-road diesel vehicles has varying source profiles based on the operational conditions.

\subsubsection{Average source profile of PM for trucks}

As shown in Table 3, the PM from trucks was dominated by carbonaceous matter $(36.8 \%)$, followed by WSIs $(4.67 \%)$ and elements $(0.941 \%)$. For individual species, sulfate and nitrate were the most abundant WSIs, and Fe was the most abundant element. Moreover, for organic matter, the average proportions of $\mathrm{n}$-alkanes, PAHs, hopanes, and steranes were $1.73,0.130$, and $0.011 \%$, respectively. C20 was the most abundant $\mathrm{n}$-alkane, and the PAHs were dominated by pyrene.

In comparison, the total carbon emissions in this study are lower than those in previous studies, whereas the WSIs and elements fractions are higher (Alves et al., 2015a; Cui et al., 2016; Schauer et al., 1999; Wu et al., 2016). Several factors have influenced these differing results such as fuel quality, driving condition, engine parameters (fuel injection timing, compression ratio, and fuel injector design), and experimental methods (Sarvi et al., 2008a, b, 2009; Sarvi and Zevenhoven, 2010). As shown in Table 3, Fe was the dominant element in studies using on-road tests and tunnels, which is similar to our results, whereas $\mathrm{Zn}$ and $\mathrm{Na}$ were dominant elements in the results obtained by a dynamometer. Therefore, the results obtained from the real-world conditions (on-road tests and tunnels) are different from those obtained in a laboratory. For organic matter, the proportion of PAHs, hopanes, and steranes to PM are consistent with the results of Schauer et al. (1999) and Cui et al. (2016). In this study, the most abundant n-alkane was $\mathrm{C} 20$, as measured by Schauer et al. (1999), and pyrene was the most abundant $\mathrm{PAH}$, as reported by Cui et al. (2016). Thus, the average profile of PM for on-road diesel trucks is relatively stable and consistent across studies. 


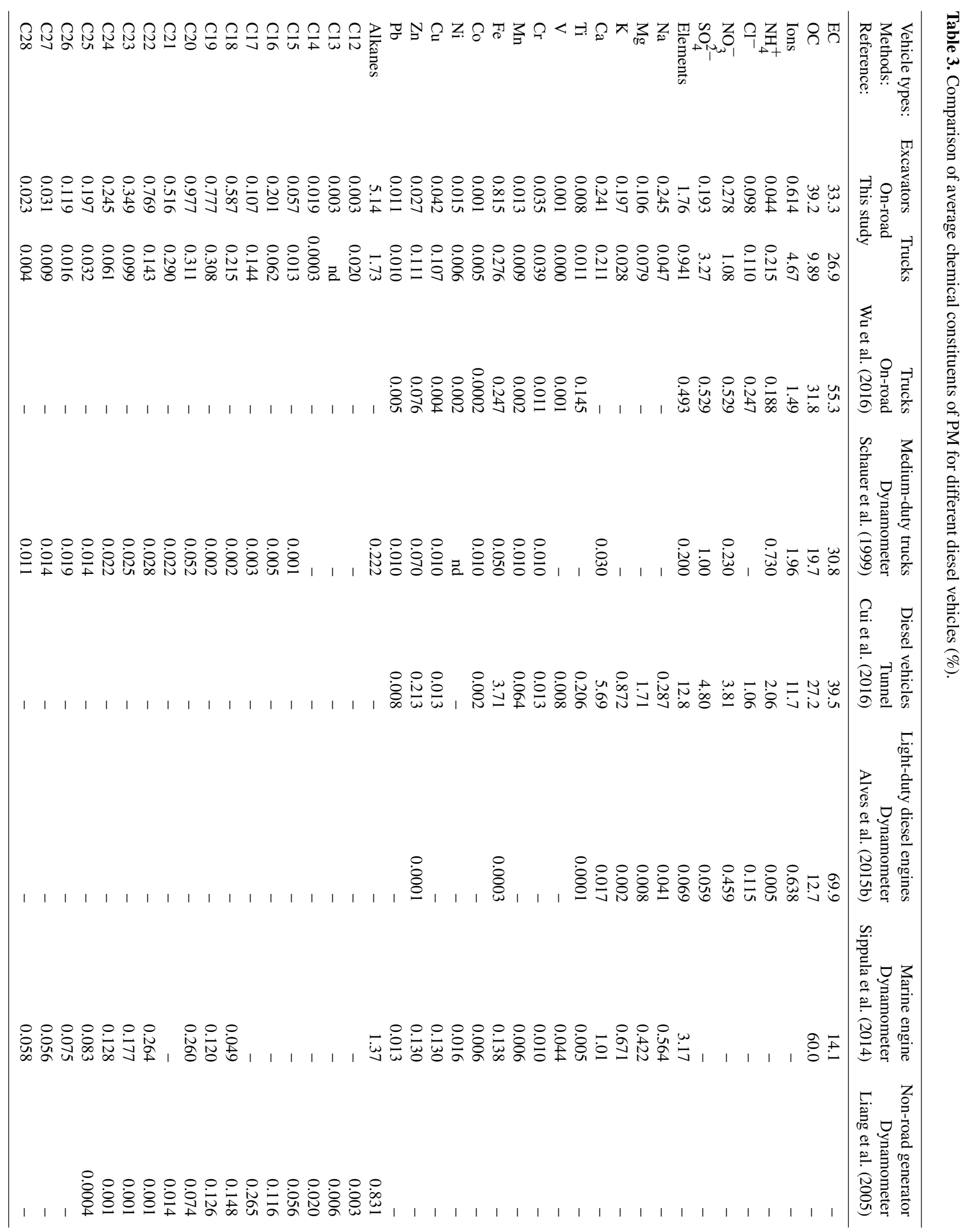




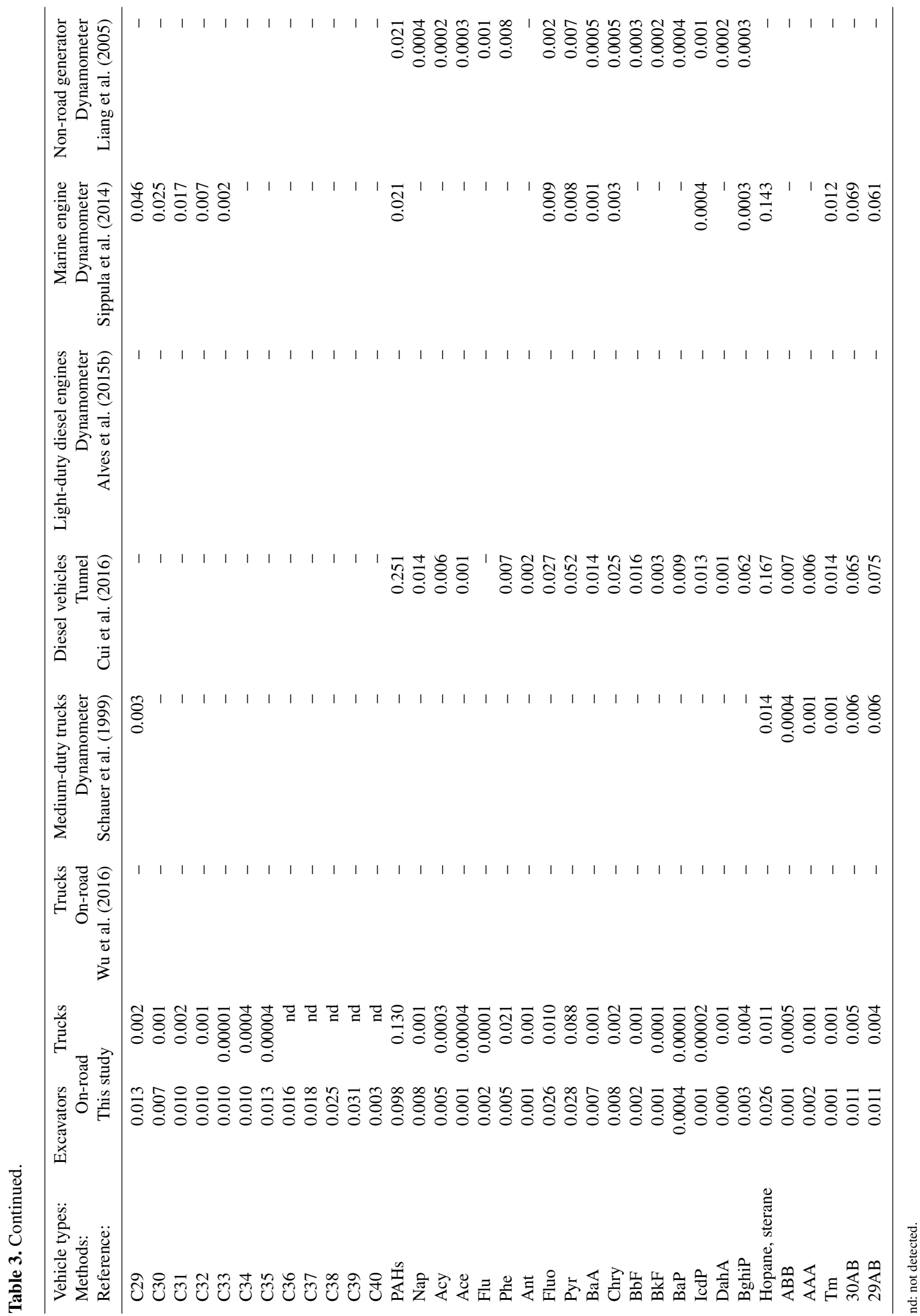




\subsection{Comparison of source profile between excavators and trucks}

The average $\mathrm{EF}_{\mathrm{PM}}$ for excavators $\left(836 \pm 801 \mathrm{mg} \mathrm{kg}^{-1}\right.$ fuel) was higher than that for diesel trucks $\left(498 \pm 234 \mathrm{mg} \mathrm{kg}^{-1}\right.$ fuel). This result is reasonable because the operations for excavators are more transient than those for trucks. Sarvi and Zevenhoven (2010) reported that PM emitted from diesel engines was typically low during steady-state operation. Although the average $\mathrm{EF}_{\mathrm{PM}}$ of excavators was higher than that of trucks, the average FFM $_{\mathrm{PM}}$ of the stage 2 excavators was $477 \mathrm{mg} \mathrm{kg}^{-1}$ fuel, which was lower than those for the China II and China III trucks. Thus, appropriate regulations formulated for non-road diesel vehicles can improve their PM emissions.

When we compared the average percentages of chemical components in PM for excavators with those for trucks, several differences were found. In general, the carbonaceous $(95.9 \%)$ and elements $(1.76 \%)$ fractions for excavators were higher than those for diesel trucks (42.8 and $0.94 \%$, respectively). As shown in Figure 8, the structures of different ring PAHs in the exhaust from excavators and trucks varied sharply, particularly for 5- and 6-ring PAHs. However, the average percentage of total PAHs in the PM was consistent between the excavators and trucks. Due to their lipophilicity, high-molecular-weight (5- and 6-ring) PAHs are considered to be more harmful to human health than other PAHs. For further distinction, BaPeq was used in this study. The range of total BaPeq for trucks was 5.32 (T5) to 155 (T3) $\mathrm{ng} \mathrm{m}^{-3}$, while for excavators the range of total BaPeq was 38.3 (E1) to 3637 (E4) $\mathrm{ng} \mathrm{m}^{-3}$. Moreover, the total average BaPeq for the excavators was 31 times than that for the diesel trucks. Almost all of the PAH BaP $\mathrm{Bq}_{\text {eq }}$ values calculated in this study for trucks and excavators are higher than the concentrations that cause $1 / 10000$ of the carcinogenic risk, according to the World Health Organization (WHO). Owing to the adverse environmental effects and health hazards caused by carbonaceous compositions, elements, and PAHs, the PM emissions from excavators require urgent control.

\section{Conclusions}

This study reported the characteristics of PM source profiles for excavators and the EFPM values for exhaust from excavators and trucks with different emission standards and those used in different operation modes, or road conditions. The EFPM for different excavators ranged from 96.5 to $2323 \mathrm{mg} \mathrm{kg}^{-1}$ fuel, with an average of $810 \mathrm{mg} \mathrm{kg}^{-1}$ fuel and showed a high correlation $\left(R^{2}=0.79, P<0.01\right)$ with the fuel sulfur contents. The highest average $\mathrm{EF}_{\mathrm{PM}}$ for working excavators ( $904 \pm 979 \mathrm{mg} \mathrm{kg}^{-1}$ fuel) might be the result of higher engine load, which causes lower air-fuel ratios. The average $\mathrm{EF}_{\mathrm{PM}}$ for the tested diesel trucks with different emission standards and vehicle sizes under different driving
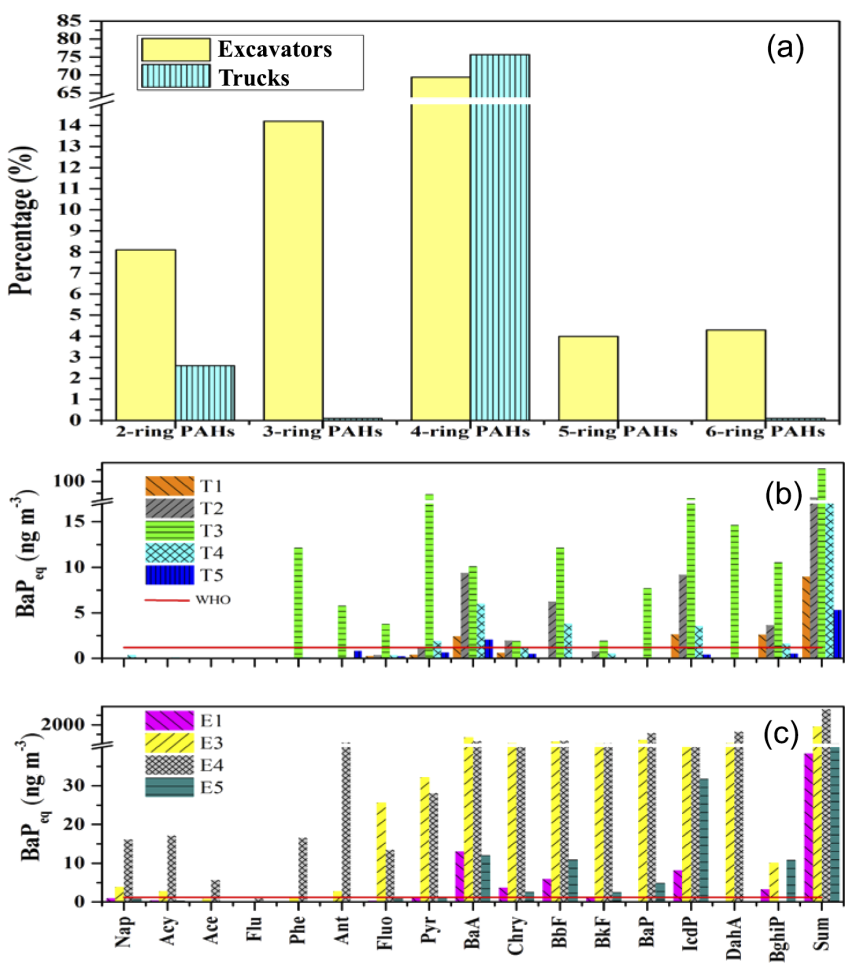

Figure 8. Percentages of each ring PAHs to total PAHs (a). BaPeq for parent PAHs in each tested trucks (b) and excavators (c).

conditions was $498 \pm 234 \mathrm{mg} \mathrm{kg}^{-1}$ fuel. The average $\mathrm{EF}_{\mathrm{PM}}$ for excavators was decreased by $58 \%$ from pre-stage 1 to stage 2. Moreover, the reductions in $\mathrm{EF}_{\mathrm{PM}}$ from the China II to the China IV truck and from the China III to the China IV truck were 63.5 and $65.6 \%$, respectively. This indicates that the improvements in the emission standards and fuel quality for diesel trucks and excavators have significant effects on the reduction of PM emissions. It should be noticed that the $\mathrm{EF}_{\mathrm{PM}}$ for China III and light-duty diesel trucks were higher than those for the other trucks, which could be a result of poor driving conditions that include low average and highly variable speeds. For each excavator, the carbon component $(\mathrm{OM}+\mathrm{EC})$ was the dominant fraction and accounted for approximately $74.1-123 \%$ of the PM. The average ranges of WSIs, elements, n-alkanes, PAHs, hopane, and sterane fractions for each excavator were $0.335-1-21,0.163-7.50,3.6-$ $9.6,0.03-0.24$, and $0.001-0.09 \%$, respectively. In contrast to the other excavators, $\mathrm{Zn}$ and $\mathrm{Cu}$ were the second and third most abundant elements in exhaust from E4, which might to the result of poor fuel quality and the vehicle's age. Additionally, the element fractions for the two excavators produced in 2013 (E1: 1.42\%; E6: 7.50\%) were higher than those of other excavators, which might indicate that the element emissions control deteriorated and that more stringent control technology should be developed. For excavators, the ranges of the $\mathrm{BaA} /(\mathrm{BaA}+\mathrm{Chry})$, IcdP / (IcdP + BghiP $)$, and Flua / (Flua + Pry) ratios were 0.26-0.86, 0.20-1.0, and 
$0.24-0.87$, respectively, with averages of $0.47 \pm 0.27,0.44 \pm$ 0.38 and $0.48 \pm 0.27$, respectively. For diesel trucks, the total carbonaceous composition (OM + EC) accounted for $44.0 \%$ (T1), $27.9 \%$ (T2), $43.9 \%$ (T3), $51.6 \%$ (T4), and $46.3 \%$ (T5) of PM. For T2, WSIs (13.8\%) were the most significant fraction of PM after OC, and were higher than those for the other trucks by a factor of 4-10. The n-alkanes, PAHs, hopane, and steranes fractions ranged from 0.85 to $4.78,0.01$ to 0.54 , and 0.002 to $0.024 \%$ for trucks, respectively. In comparison with the results from other studies, the characteristics of the average source profiles for different types of non-road diesel vehicles varied sharply, whereas those for on-road diesel vehicles showed more stability. Although the PAH fractions for the excavators and trucks were similar, the total $\mathrm{BaP}_{\text {eq }}$ that was used to evaluate the carcinogenic risk was 31 times for excavators than for trucks.

Data availability. Data used in this study can be provided by Cui Min (15212219177@163.com).

\section{The Supplement related to this article is available online at https://doi.org/10.5194/acp-17-6779-2017-supplement.}

Competing interests. The authors declare that they have no conflict of interest.

Acknowledgements. This study was supported by the CAS Strategic Research Program (no. XDB05030303), the Natural Scientific Foundation of China (nos. 41473091 and 41273135), the Fundamental Research Funds for the Central Universities, and the National Distinguished Young Scholar Science Fund of the National Natural Science Foundation of China (no. 41325020).

Edited by: Gregory Frost

Reviewed by: two anonymous referees

\section{References}

Adar, S. D., D’Souza, J., Sheppard, L., Kaufman, J. D., Hallstrand, T. S., Davey, M. E., Sullivan, J. R., Jahnke, J., Koenig, J., Larson, T. V., and Liu, L. J. S.: Adopting clean fuels and technologies on school buses. pollution and health impacts in children, Am. J. Resp. Crit. Care., 191, 1413-1421, 2015.

Aggarwal, P. and Jain, S.: Impact of air pollutants from surface transport sources on human health: a modeling and epidemiological approach, Environ. Int., 83, 146-157, 2015.

Almeida, S. M., Pio, C. A., Freitas, M. C., Reis, M. A., and Trancoso, M. A.: Approaching $\mathrm{PM}_{2.5}$ and $\mathrm{PM}_{2.5-10}$ source apportionment by mass balance analysis, principal component analysis and particle size distribution, Sci. Total Environ., 368, 663-674, 2006.
Alves, C. A., Barbosa, C., Rocha, S., Calvo, A., Nunes, T., Cerqueira, M., Pio, C., Karanasiou, A., and Querol, X.: Elements and polycyclic aromatic hydrocarbons in exhaust particles emitted by light-duty vehicles, Environ. Sci. Pollut. Res., 22, 1152611542, 2015a.

Alves, C. A., Lopes, D. J., Calvo, A. I., Evtyugina, M., Rocha, S., and Nunes, T.: Emissions from light-duty diesel and gasoline in-use vehicles measured on chassis dynamometer test cycles, Aerosol Air Qual. Res., 15, 99-116, 2015 b.

An, P. Z., Sun, W. C., Li, G. L., Tan, M. Z., Lai, C. J., and Chen, S. B.: Characteristics of particle size distributions about emissions in a common-rail diesel engine with biodiesel blends, Procedia Environmental Sciences, 11, 1371-1378, 2011.

CCCMIY (Compiling committee of China machinery industry yearbook) and CCMA (China Construction Machinery Association): China construction machinery industry yearbook. China Machine Press Place, Published, 2013

Chen, F., Hu, W., and Zhong, Q.: Emissions of particle-phase polycyclic aromatic hydrocarbons (PAHs) in the Fu Gui-shan Tunnel of Nanjing, China, Atmos. Res., 124, 53-60, 2013.

Cheng, M. T., Chen, H. J., Young, L. H., Yang, H. H., Tsai, Y. I., Wang, L. C., Lu, J. H., and Chen, C. B.: Carbonaceous composition changes of heavy-duty diesel engine particles in relation to biodiesels, aftertreatments and engine loads, J. Hazard. Mater., 297, 234-240, 2015.

Cheng, Y., Zheng, M., He, K. B., Chen, Y., Yan, B., Russell, A. G., Shi, W., Jiao, Z., Sheng, G., Fu, J., and Edgerton, E. S.: Comparison of two thermal-optical methods for the determination of organic carbon and elemental carbon: results from the southeastern United States, Atmos. Environ., 45, 1913-1918, 2011.

Chow, J. C., Watson, J. G., Lowenthal, D. H., Antony Chen, L. W., and Motallebi, N.: $\mathrm{PM}_{2.5}$ source profiles for black and organic carbon emission inventories, Atmos. Environ., 45, 5407-5414, 2011.

Cocker, D. R., Shah, S. D., Johnson, K. C., Zhu, X. N., Miller, J. W., and Norbeck, J. M.: Development and application of a mobile laboratory for measuring emissions from diesel engines. 2. Sampling for toxics and particulate matter, Environ. Sci. Technol., 38, 6809-6816, 2004.

Cui, M., Chen, Y., Tian, C., Zhang, F., Yan, C., and Zheng, M.: Chemical composition of $\mathrm{PM}_{2.5}$ from two tunnels with different vehicular fleet characteristics, Sci. Total Environ., 550, 123-132, 2016.

Fu, M. L., Ge, Y. S., Tan, J. W., Zeng, T., and Liang, B.: Characteristics of typical non-road machinery emissions in China by using portable emission measurement system, Sci. Total Environ., 437, 255-261, 2012.

Huang, C., Chen, C. H., Li, L., Cheng, Z., Wang, H. L., Huang, H. Y., Streets, D. G., Wang, Y. J., Zhang, G. F., and Chen, Y. R.: Emission inventory of anthropogenic air pollutants and VOC species in the Yangtze River Delta region, China, Atmos. Chem. Phys., 11, 4105-4120, https://doi.org/10.5194/acp11-4105-2011, 2011.

Huo, H., Yao, Z. L., Zhang, Y. Z., Shen, X. B., Zhang, Q., and He, K. B.: On-board measurements of emissions from diesel trucks in five cities in China, Atmos. Environ., 54, 159-167, 2012.

IARC (International Agency for Research on Cancer): Diesel Engine Exhaust Carcinogenic, WHO, 2012. 
Kasper, M., Sattler, K., Siegmann, K., Matter, U., and Siegmann, H. C.: The influence of fuel additives on the formation of carbon during combustion, J. Aerosol Sci., 30, 217-225, 1999.

Li, D. L., Wu, Y., Zhou, Y., Du, X., and Fu, L. X.: Fuel consumption and emission inventory of typical construction equipments in China, Environm. Sci., 33, 518-524, 2012.

Liang, F. Y., Lu, M. M., Keener, T. C., Liu, Z. F., and Khang, S. J.: The organic composition of diesel particulate matter, diesel fuel and engine oil of a non-road diesel generator, J. Environ. Monitor., 7, 983-988, 2005.

Lin, Y.-C., Tsai, C.-J., Wu, Y.-C., Zhang, R., Chi, K.-H., Huang, Y.-T., Lin, S.-H., and Hsu, S.-C.: Characteristics of trace metals in traffic-derived particles in Hsuehshan Tunnel, Taiwan: size distribution, potential source, and fingerprinting metal ratio, Atmos. Chem. Phys., 15, 4117-4130, https://doi.org/10.5194/acp15-4117-2015, 2015.

Liu, H., He, K. B., Lents, J. M., Wang, Q. D., and Tolvett, S.: Characteristics of diesel truck emission in China based on portable emissions measurement systems, Environ. Sci. Technol., 43, 9507-9511, 2009.

Liu, L. Y., Wang, J. Z., Wei, G. L., Guan, Y. F., and Zeng, E. Y.: Polycyclic aromatic hydrocarbons (PAHs) in continental shelf sediment of China: implications for anthropogenic influences on coastal marine environment, Environ. Pollut., 167, 155-162, 2012

Liu, Z. F., Lu, M. M., Birch, M. E., Keener, T. C., Khang, S. J., and Liang, F. Y.: Variations of the particulate carbon distribution from a nonroad diesel generator, Environ. Sci. Technol., 39, 7840-7844, 2005.

Liu, Z. G., Wall, J. C., Ottinger, N. A., and McGuffin, D.: Mitigation of PAH and nitro-PAH emissions from nonroad diesel engines, Environ. Sci. Technol., 49, 3662-3671, 2015.

Longhin, E., Gualtieri, M., Capasso, L., Bengalli, R., Mollerup, S., Holme, J. A., Ovrevik, J., Casadei, S., Di Benedetto, C., Parenti, P., and Camatini, M.: Physico-chemical properties and biological effects of diesel and biomass particles, Environ. Pollut., 215, 366-375, 2016.

Mancilla, Y. and Mendoza, A.: A tunnel study to characterize $\mathrm{PM}_{2.5}$ emissions from gasoline-powered vehicles in Monterrey, Mexico, Atmos. Environ., 59, 449-460, 2012.

MEP (Ministry of Environmental Protection of China): The technical guide for compiling primary source emission inventories of atmospheric fine particulate matter, Beijing, 2014.

MEP (Ministry of Environmental Protection of China): China vehicle environmental management annual report, Beijing, 7 pp., 2016.

MEPPRC (Ministry of Environmental Protection of the People's Republic of China): Technical guide for the preparation of a single source emission inventory of atmospheric fine particulate matter: 12 pp., Beijing, 2014.

Mirante, F., Alves, C., Pio, C., Pindado, O., Perez, R., Revuelta, M. A., and Artinano, B.: Organic composition of size segregated atmospheric particulate matter, during summer and winter sampling campaigns at representative sites in Madrid, Spain, Atmos. Res., 132, 345-361, 2013.

Oanh, N. T. K., Thiansathit, W., Bond, T. C., Subramanian, R., Winijkul, E., and Paw-armart, I.: Compositional characterization of $\mathrm{PM}_{2.5}$ emitted from in-use diesel vehicles, Atmos. Environ., 44, 15-22, 2010.
Pietikainen, M., Valiheikki, A., Oravisjarvi, K., Kolli, T., Huuhtanen, M., Niemi, S., Virtanen, S., Karhu, T., and Keiski, R. L.: Particle and $\mathrm{NO}_{x}$ emissions of a non-road diesel engine with an SCR unit: the effect of fuel, Renew. Energ., 77, 377-385, 2015.

Pio, C., Mirante, F., Oliveira, C., Matos, M., Caseiro, A., Oliveira, C., Querol, X., Alves, C., Martins, N., Cerqueira, M., Camões, F., Silva, H., and Plana, F.: Size-segregated chemical composition of aerosol emissions in an urban road tunnel in Portugal, Atmos. Environ., 71, 15-25, 2013.

Rogge, W. F., Hildemann, L. M., Mazurek, M. A., Cass, G. R., and Simoneit, B. R. T.: Sources of fine organic aerosol. 2. Noncatalyst and catalyst-equipped automobiles and heavy-duty diesel trucks, Environ. Sci. Technol., 27, 636-651, 1993.

Ruiz, F. A., Cadrazco, M., López, A. F., Sanchez-Valdepeñas, J., and Agudelo, J. R.: Impact of dual-fuel combustion with nbutanol or hydrous ethanol on the oxidation reactivity and nanostructure of diesel particulate matter, Fuel, 161, 18-25, 2015.

Sarvi, A., Fogelholm, C. J., and Zevenhoven, R.: Emissions from large-scale medium-speed diesel engines: 1 . Influence of engine operation mode and turbocharger, Fuel Process. Technol., 89, 510-519, 2008a.

Sarvi, A., Fogelholm, C. J., and Zevenhoven, R.: Emissions from large-scale medium-speed diesel engines: 2. Influence of fuel type and operating mode, Fuel Process. Technol., 89, 520-527, 2008b.

Sarvi, A., Kilpinen, P., and Zevenhoven, R.: Emissions from largescale medium-speed diesel engines: 3 . Influence of direct water injection and common rail, Fuel Process. Technol., 90, 222-231, 2009.

Sarvi, A. and Zevenhoven, R.: Large-scale diesel engine emission control parameters, Energy, 35, 1139-1145, 2010.

Schauer, J. J., Kleeman, M. J., Cass, G. R., and Simoneit, B. R. T.: Measurement of emissions from air pollution sources. 2. C1 through C-30 organic compounds from medium duty diesel trucks, Environ. Sci. Technol., 33, 1578-1587, 1999.

SEPA (State Environmental Protection Administration) and SAQSIQ (State Administration for Quality Supervision and Inspection and Quarantine): Limits and measurement methods for emissions from light-duty vehicles (I), Beijing, 2001.

SEPA (State Environmental Protection Administration) and SAQSIQ (State Administration for Quality Supervision and Inspection and Quarantine): Limits and measurements methods for exhaust pollutants from diesel engines of non-road mobile machinery (I, II), 2007.

SEPA (State Environmental Protection Administration) and SAQSIQ (State Administration for Quality Supervision and Inspection and Quarantine): General diesel fuels, 2015.

Shah, S. D., Ogunyoku, T. A., Miller, J. W., and Cocker, D. R.: On-road emission rates of PAH and n-alkane compounds from heavy-duty diesel vehicles, Environ. Sci. Technol., 39, 52765284, 2005.

Sippula, O., Stengel, B., Sklorz, M., Streibel, T., Rabe, R., Orasche, J., Lintelmann, J., Michalke, B., Abbaszade, G., Radischat, C., Groger, T., Schnelle-Kreis, J., Harndorf, H., and Zimmermann, R.: Particle emissions from a marine engine: chemical composition and aromatic emission profiles under various operating conditions, Environ. Sci. Technol., 48, 11721-11729, 2014.

USEPA (Environmental Protection Agency): Nonroad engine and vehicle emission study, USA, p. 45, 1991. 
USEPA (Environmental Protection Agency): Air radiation. reducing air pollution from nonroad engines, USEPA, USA, available at: http://www.epa.gov/otaq/cleaner-nonroad/f03011. pdf, last access: August 2016, 2003.

USEPA (Environmental Protection Agency) Evaluation of black carbon emission reductions from mining trucks in russia: the case of the murmansk region, USEPA, USA, 2015.

Wang, F., Li, Z., Zhang, K. S., Di, B. F., and Hu, B. M.: An overview of non-road equipment emissions in China, Atmos. Environ., 132, 283-289, 2016.

Wang, X., Wang, W., Liu, X., Cheng, H., and Xu, X.: Health risk assessment of PAHs in fine particulate matter in Beijing, Environ. Chem., 27, 393-394, 2008.

Wang, X. W., Song, C. L., Lv, G., Song, J. N., Li, H., and Li, B.: Evolution of in-cylinder polycyclic aromatic hydrocarbons in a diesel engine fueled with n-heptane and n-heptane/toluene, Fuel, 158, 322-329, 2015.

Wang, Y. F., Huang, K. L., Li, C. T., Mi, H. H., Luo, J. H., and Tsai, P. J.: Emissions of fuel metals content from a diesel vehicle engine, Atmos. Environ., 37, 4637-4643, 2003.

Wu, B., Shen, X., Cao, X., Yao, Z., and Wu, Y.: Characterization of the chemical composition of $\mathrm{PM}_{2.5}$ emitted from on-road China III and China IV diesel trucks in Beijing, China, Sci. Total Environ., 551-552, 579-589, 2016.

Wu, B., Shen, X., Cao, X., Zhang, W., Wu, H., and Yao, Z.: Carbonaceous composition of $\mathrm{PM}_{2.5}$ emitted from on-road China III diesel trucks in Beijing, China, Atmos. Environ., 116, 216-224, 2015.

Yu, W. and Yang, T.: Formation mechanism and technical measured for reducing emissions of diesel engine, Transportation energy saving and environmental protection, 03, 17-19, 2007.
Yue, X., Wu, Y., Hao, J. M., Pang, Y., Ma, Y., Li, Y., Li, B. S., and Bao, X. F.: Fuel quality management versus vehicle emission control in China, status quo and future perspectives, Energ. Policy, 79, 87-98, 2015.

Yunker, M. B., Macdonald, R. W., Vingarzan, R., Mitchell, R. H., Goyette, D., and Sylvestre, S.: PAHs in the Fraser River basin: a critical appraisal of PAH ratios as indicators of PAH source and composition, Org. Geochem., 33, 489-515, 2002.

Zhang, L. J., Zheng, J. Y., Yin, S. S., Peng, K., and Zhong, L. J.: Development of non-road mobile source emission inventory for the Pearl River Delta region, Environmental Science (China), 31, 886-891, 2010.

Zhang, F., Chen, Y., Tian, C., Lou, D., Li, J., Zhang, G., and Matthias, V.: Emission factors for gaseous and particulate pollutants from offshore diesel engine vessels in China, Atmos. Chem. Phys., 16, 6319-6334, https://doi.org/10.5194/acp-166319-2016, 2016.

Zhang, Y., Yao, Z., Shen, X., Liu, H., and He, K.: Chemical characterization of $\mathrm{PM}_{2.5}$ emitted from on-road heavy-duty diesel trucks in China, Atmos. Environ., 122, 885-891, 2015.

Zhang, Z. H. and Balasubramanian, R.: Influence of butanol-diesel blends on particulate emissions of a non-road diesel engine, Fuel, 118, 130-136, 2014.

Zheng, X., Wu, Y., Jiang, J. K., Zhang, S. J., Liu, H., Song, S. J., Li, Z. H., Fan, X. X., Fu, L. X., and Hao, J. M.: Characteristics of nn-road diesel vehicles: black carbon emissions in Chinese cities based on portable emissions measurement, Environ. Sci. Technol., 49, 13492-13500, 2015. 